\title{
BMJ Factors influencing the length of Open hospital stay among patients resident in Blackpool admitted with COPD: a cross-sectional study
}

\author{
Gabriel Agboado, ${ }^{1}$ Jonathan Peters, ${ }^{2}$ Lynn Donkin ${ }^{2}$
}

To cite: Agboado G, Peters J, Donkin L. Factors influencing the length of hospital stay among patients resident in Blackpool admitted with COPD: a cross-sectional study. BMJ Open 2012;2: e000869. doi:10.1136/ bmjopen-2012-000869

- Prepublication history and additional material for this paper are available online. To view these files please visit the journal online (http://dx.doi.org/10.1136/ bmjopen-2011-000869)

Received 26 January 2012 Accepted 27 July 2012

This final article is available for use under the terms of the Creative Commons Attribution Non-Commercial 2.0 Licence; see http://bmjopen.bmj.com

${ }^{1}$ Public Health Department, NHS Wandsworth, London, UK

2Public Health Department, NHS Blackpool, Blackpool, UK

Correspondence to Dr Gabriel Agboado; gagboado@nhs.net

\section{ABSTRACT}

Objectives: To identify the differential effects of patient, health service, temporal and geographic factors on length of stay (LOS) for chronic obstructive pulmonary disease (COPD)-related admissions. Design: We used stratified Cox proportional hazard model to evaluate the association between LOS and patient, health service, temporal and geographical factors. Setting: Patients resident in Blackpool, North West England, admitted to the local hospital with COPD.

Participants: We used the Admitted Patient Care General Episode Commissioning Dataset for the period 1 April 2005-31 March 2010. We analysed records of admission spells among patients resident in Blackpool aged 40 years or older admitted with a primary diagnosis of COPD.

Results: There were 2410 admissions meeting the inclusion criteria over the period. These admissions were attributed to 1172 COPD patients, an average of 2.06 admissions per patient. The median LOS was 6 days ( $95 \% \mathrm{Cl} 6$ to 6) while the mean was 9.8 days (95\% Cl 9.1 to 10.5 ). Patients were $22 \%$ more likely to be discharged earlier in 2009/2010 compared with 2005/2006 (adjusted HR 1.22; $p=0.0100$ ). LOS was associated with socioeconomic deprivation with those in the most deprived areas being $35 \%$ less likely to be discharged earlier compared with those from the least deprived areas (adjusted HR 0.65; $p=0.0010$ ).

Conclusions: LOS among COPD patients have reduced over the period of the study. Age, deprivation, Charlson index, specialty of admission and cause of exacerbations were independently associated with LOS. Though there were no significant associations between LOS and season of admission and distance from hospital, there were significant variations in LOS associated with these variables based on selected patient characteristics.

\section{INTRODUCTION}

Chronic obstructive pulmonary disease (COPD) is projected to become the third most common cause of morbidity worldwide by $2020 .{ }^{1}$ In England COPD prevalence is estimated at between $2 \%$ and $4 \% .^{2}$ During the 2009/2010 financial year COPD admissions

\section{ARTICLE SUMMARY}

\section{Article focus}

The focus of this study is on:

- The length of hospital stay (LOS) among patients admitted with chronic obstructive pulmonary disease (COPD) in Blackpool, a spearhead unitary local authority in the North West of England admitted to the local hospital.

- The associations between LOS and patient, health service, temporal and geographical factors.

Key messages

- LOS among COPD patients have reduced over the study period.

- COPD patient from the most deprived areas stayed longer in hospital compared with their counterpart from the most affluent areas.

- Effect of season on LOS varied by the level of deprivation.

Strengths and limitations of this study

- Our study provided a unique insight into the experiences of COPD patients from a small geographical area using a local hospital.

- Our study takes into account case-mix and interaction effects among predictor variables.

- Incompleteness and inaccuracy are the main problems associated with routine data we used.

- We could not assess the effects of other potential confounders on LOS because the dataset we used did not contain information on these variables.

- We used population level measure of deprivation (Index of Multiple Deprivation) that could predispose to ecological fallacy.

accounted for about $1.1 \%$ of in-patient finished consultant episodes and $1.5 \%$ of all finished consultant episodes bed days. ${ }^{3}$

A high proportion of the costs of managing COPD is attributed to exacerbations. This varies from $40 \%$ to $57 \%$ of the total direct costs and can be as high as $63 \%$ in severely affected patients. ${ }^{4}$ Inpatient admission is a major cost driver in COPD management $^{56}$ accounting for about $54 \%$ of the 
direct cost associated with its management in the UK. ${ }^{7}$ The cost of hospitalisation is also significantly influenced by the length of hospital stay. ${ }^{8}$

Though many studies on improving admission outcomes for COPD patients and improving efficiency tended to focus on reducing duration of in-patient care ${ }^{9} 10$ no optimum length of stay (LOS) has been consistently described. International trends in COPD-related hospitalisation have shown that although the average LOS has decreased since 1972, admissions rates have increased in patients aged 45 years or older. ${ }^{8}$ This has led some to suggest that efforts to cut down the duration of inpatient episodes may result in a 'revolving door' phenomenon. ${ }^{11}$

According to the English Department of Health 2010 COPD strategy consultation document ${ }^{12}$ the LOS for COPD-related admissions has reduced to a median of 5 days in 2008 from a median of 6 days in 2003 but re-admission rates have been increasing. This is despite the fact that relatively few patients with exacerbations are admitted. ${ }^{13}$ Taking cognizant of these patterns, the consultation document identified a key objective of reducing 'length of stay for people with COPD, where appropriate'. ${ }^{12}$

Our objective for this study is to identify the differential effects of patient, health service, temporal and geographical factors on LOS for COPD-related admissions. Understanding of these influences will help optimise care for COPD patients needing hospital admissions.

\section{METHODS}

\section{Study setting and predictor variables}

Blackpool is a spearhead unitary local authority in the North West of England with an estimated population of $139974 .{ }^{14}$ The majority of population live in areas classified within the fifth-most deprived national deprivation quintile. The Blackpool Teaching Hospitals NHS Foundation Trust (BTH) is the main provider of inpatient hospital care for Blackpool residents.

In tandem with national and international trends, COPD prevalence in Blackpool continues to increase. Estimates based on general practice Quality Outcome Framework (QOF) data showed that the prevalence in Blackpool was $2.7 \%$ in $2009 / 2010$ up from $2.3 \%$ in $2004 / 2005$. The 2009/2010 figure was significantly higher than the North West average of 2.1\% and England average of 1.6\%. ${ }^{15}$

The predictor variables considered in the study are listed in box 1 . These were selected because of their well-established association with health outcomes such as life expectancy, quality of life, uptake of preventive services and treatment outcomes, ${ }^{16}$ health service use ${ }^{17}$ and seasonal variations in mortality. ${ }^{18}$

\section{Data}

We used the Admitted Patient Care General Episode Commissioning Dataset for the period 1 April 2005-31 March 2010 for this study. This dataset normally covers all NHS and private provider admission spells in any

\section{Box 1: Predictor variables considered}

Sociodemographic variables

- Age at admission

- Gender

- Socioeconomic deprivation status of place of residence

Temporal and Geographical Factors

- Financial year of admission

- Season of admission

- Distance of place of residence from hospital

Health and Health Service Factors

- Primary diagnosis at admission

- Charlson comorbidity index at admission

- Treatment specialty

- Patients' GP practice location

hospital in England under the care of a consultant, midwife or nurse. ${ }^{19}$ A provider spell is the time that a patient stays with one hospital care provider from admission to discharge, transfer or death. ${ }^{20}$

We extracted for analyses records of admission spells for patients resident in Blackpool aged 40 years or older admitted to BTH with a primary diagnosis of COPD (ICD-10 code J40-J44) ${ }^{21}$ and with no primary procedures (invasive or non-invasive) carried out or recorded. NHS numbers were anonymised and used as unique identifiers for admissions attributable to a patient.

Patients were also grouped into four age bands (40-59, 60-69, 70-79 and 80+). To identify the subclassifications of COPD conditions, ICD-10 codes were linked to their respective descriptions. ${ }^{21}$ We estimated the Charlson comorbidity index ${ }^{22}$ using the secondary diagnoses recorded at admission. We subsequently grouped the patients into three indices bands namely 1, 2 and 3+.

Postcodes of places of residence were linked to the 2010 English Index of Multiple Deprivation (IMD), ${ }^{23}$ which are composite scores derived from seven deprivation domains, using the lower super output codes. The scores were grouped into the national IMD quintiles. The higher the score, the more deprived an area is. We classified the seasons of admission using the Office for National Statistics (ONS) classifications used for the excess winter deaths calculations. ${ }^{18}$

To identify patient's general practitioner (GP) practice, practice codes were linked to their respective locations and classified as from Blackpool or from outside Blackpool because there were very small numbers of admissions recorded for some of the practices. We estimated the shortest distance (in kilometres) between patients' places of residence and the hospital using the geographical co-ordinates (Easting and Northing) associated with postcodes. These distances were categorised into quintiles.

\section{Outcomes}

In this study we sought to identify the factors associated with the LOS among Blackpool COPD patients. The 
factors considered in the analyses are listed in box 1 . The main outcome measures were the median and mean length of hospital stay, and HRs of being discharged earlier from hospital associated with the variables.

\section{Statistical analyses}

We calculated LOS from the date of admission and the date of discharge. Discharges to usual places of residence, hospices and care homes were considered the endpoints for each admission spell while admissions resulting in deaths and those resulting in transfers to other NHS hospital care providers were censored.

We used the Kaplan-Meier method to estimate median and restricted mean LOS because the LOS data were positively skewed ${ }^{24}$ and because of the presence of censoring. ${ }^{25}$ To identify factors independently associated with LOS we used Cox proportional hazard model for both univariate and multivariate analyses. We tested the proportional hazard assumption using the Schoenfeld residuals test. ${ }^{26}$ The assumption did not hold for gender in both univariate and multivariate models (table 1) hence we used the stratified Cox model (stratified by gender) for the final multivariate model that included all the remaining variables. We also adjusted for clustering at patient level because there were multiple admissions recorded for some of the patients over the period. The results from the multivariate model containing all the main variables were reported as adjusted HRs.

We added interaction terms for age group and IMD quintile (age group $\times$ IMD quintile) and age group and season of admission (age group $\times$ season) to the final model in turn to assess any interaction between these factors. We also evaluated interactions between season and level of deprivation (season $\times$ IMD quintile), season and distance from hospital (season $\times$ distance), and patient's age and distance from hospital (agexdistance).

We used the likelihood ratio test to evaluate the contribution of the interaction terms to the overall fit of the models. We did not use the likelihood ratio test for the main effects to identify those that contribute significantly

Table 1 Variations in length of stay by patient sociodemographic variables

\begin{tabular}{|c|c|c|c|c|c|c|c|c|c|}
\hline Variable & $\begin{array}{l}\text { Number of } \\
\text { admissions } \\
\text { (\%) }\end{array}$ & $\begin{array}{l}\text { Median } \\
\text { LOS } \\
(95 \% \mathrm{Cl})\end{array}$ & $\begin{array}{l}\text { Mean LOS } \\
(95 \% \mathrm{Cl})\end{array}$ & $\begin{array}{l}\text { Unadjusted } \\
\text { HR (95\% Cl) }\end{array}$ & $p$ & $\begin{array}{l}\text { p For PH } \\
\text { test }\end{array}$ & $\begin{array}{l}\text { Adjusted HR† } \\
(95 \% \mathrm{Cl})\end{array}$ & $p$ & $\begin{array}{l}\text { p For } \\
\text { PH } \\
\text { test }^{\star}\end{array}$ \\
\hline \multicolumn{10}{|c|}{ Age group } \\
\hline $40-59$ & $410(17.0 \%)$ & 5 (5 to 6$)$ & $\begin{array}{l}6.96 \\
\text { (6.13 to } 7.80)\end{array}$ & 1 & - & - & 1 & - & - \\
\hline $60-69$ & $741(30.7 \%)$ & 5 (5 to 6$)$ & $\begin{array}{l}7.11 \\
\text { (6.57 to } 7.65)\end{array}$ & $\begin{array}{l}0.95 \\
(0.79 \text { to } 1.15)\end{array}$ & 0.6010 & 0.5842 & $\begin{array}{l}0.90 \\
(0.77 \text { to } 1.05)\end{array}$ & 0.1830 & 0.8206 \\
\hline $70-79$ & 788 (32.7\%) & $6(6$ to 7$)$ & $\begin{array}{l}10.92 \\
\text { (9.77 to } 12.07)\end{array}$ & $\begin{array}{l}0.71 \\
(0.58 \text { to } 0.86)\end{array}$ & $<0.0001$ & 0.7668 & $\begin{array}{l}0.69 \\
(0.59 \text { to } 0.82)\end{array}$ & $<0.0001$ & 0.2508 \\
\hline $80+$ & 471 (19.5\%) & 7 (7 to 8$)$ & $\begin{array}{l}14.51 \\
(11.84 \text { to } \\
17.18)\end{array}$ & $\begin{array}{l}0.58 \\
(0.48 \text { to } 0.71)\end{array}$ & $<0.0001$ & 0.9745 & $\begin{array}{l}0.59 \\
(0.50 \text { to } 0.70)\end{array}$ & $<0.0001$ & 0.8858 \\
\hline Total & $2410(100 \%)$ & $6(6$ to 6$)$ & $\begin{array}{l}9.79 \\
\text { (9.09 to } 10.50)\end{array}$ & - & - & 0.6999 & - & - & - \\
\hline \multicolumn{10}{|l|}{ Gender } \\
\hline Male & $1152(47.8 \%)$ & 5 (5 to 6$)$ & $\begin{array}{l}9.46 \\
\text { (8.25 to } 10.66)\end{array}$ & 1 & - & - & - & - & - \\
\hline Female & $1258(52.2 \%)$ & 7 (6 to 7$)$ & $\begin{array}{l}10.09 \\
(9.33 \text { to } 10.85)\end{array}$ & $\begin{array}{l}0.85 \\
(0.76 \text { to } 0.96)\end{array}$ & 0.0070 & $<0.0001^{*}$ & - & - & - \\
\hline Total & $2410(100 \%)$ & $6(6$ to 6$)$ & $\begin{array}{l}9.79 \\
(9.09 \text { to } 10.50)\end{array}$ & - & - & $<0.0001^{\star}$ & - & - & - \\
\hline \multicolumn{10}{|c|}{ IMD quintileł } \\
\hline Second & $51(2.1 \%)$ & 4 (3 to 5 ) & $\begin{array}{l}5.29 \\
(4.11 \text { to } 6.46)\end{array}$ & 1 & - & - & 1 & - & - \\
\hline Third & 311 (12.9\%) & 6 (5 to 6$)$ & $\begin{array}{l}10.08 \\
(8.22 \text { to } 11.95)\end{array}$ & $\begin{array}{l}0.62 \\
(0.46 \text { to } 0.83)\end{array}$ & 0.0010 & 0.2742 & $\begin{array}{l}0.65 \\
(0.47 \text { to } 0.89)\end{array}$ & 0.0080 & 0.5542 \\
\hline Fourth & $642(26.6 \%)$ & 6 (6 to 7$)$ & $\begin{array}{l}11.76 \\
\text { (9.85 to } 13.67)\end{array}$ & $\begin{array}{l}0.57 \\
(0.44 \text { to } 0.73)\end{array}$ & $<0.0001$ & 0.5780 & $\begin{array}{l}0.57 \\
(0.42 \text { to } 0.77)\end{array}$ & $<0.0001$ & 0.3118 \\
\hline Fifth & $1406(58.3 \%)$ & 6 (6 to 6$)$ & $\begin{array}{l}8.95 \\
(8.30 \text { to } 9.60)\end{array}$ & $\begin{array}{l}0.65 \\
(0.51 \text { to } 0.84)\end{array}$ & 0.0010 & 0.9077 & $\begin{array}{l}0.59 \\
(0.43 \text { to } 0.82)\end{array}$ & 0.0010 & 0.4996 \\
\hline Total & $2410(100.0 \%)$ & 6 (6 to 6$)$ & $\begin{array}{l}9.79(9.09 \text { to } \\
10.49)\end{array}$ & - & - & 0.2134 & - & - & - \\
\hline
\end{tabular}


to the fit of the model because it was our aim to describe any association between these variables and LOS.

Only the results for the variable involved in the interaction terms were displayed because the results for the other main variables were the same as in the final model without the interaction terms. We set the statistical significance level for all the analyses at $5 \%$. We used Stata V.10 for all the analyses.

\section{RESULTS}

\section{Admission outcomes}

There were 2410 admissions meeting the inclusion criteria over the period. These admissions were attributed to 1172 COPD patients, giving an average of 2.06 admissions per patient. In all $2226(92.4 \%)$ of the admissions were discharged to usual places of residence, $12(0.5 \%)$ were discharged to local authority residential accommodation, while $7(0.3 \%)$ were to local authority-run care homes and $3(0.1 \%)$ were to local authority-run hospices. A total of $147(6.1 \%)$ of the admissions resulted in deaths while $15(0.7 \%)$ were transferred to other NHS hospital care providers. The median LOS was 6 days $(95 \%$ CI 6 to 6 ) while the mean was 9.8 days (95\% CI 9.1 to 10.5 ).

\section{Length of stay and sociodemographic variable}

Table 1 shows the variation in LOS by patient sociodemographic variables. Mean age at admission was 70.1 years (95\% CI 69.7 to 70.5$)$. The minimum age was 40 and the maximum 100 years. The highest proportion of the admissions (32.7\%) was for patients aged between 70 and 79 years while the lowest $(17.0 \%)$ was for patients aged between 40 and 59 years. There were more admissions for females (52.2\%) compared with males. More than half $(58.3 \%)$ of the admissions were for patients from the most deprived fifth quintile areas.

The LOS was significantly longer for those aged 80+ years compared with those aged 40-59 years. Compared with those aged 40-59 years, those aged $80+$ years were $41 \%$ less likely to be discharged earlier from the hospital (adjusted HR 0.59; $\mathrm{p}=<0.0001$ ) while those aged 70-79 years were $31 \%$ less likely (adjusted HR 0.69; $\mathrm{p}=<0.0001)$. There was no significant difference between the likelihood of earlier discharge for those aged $40-59$ years and 60-69 years (adjusted HR 0.90; $\mathrm{p}=0.1830$ ).

Females had a slightly longer LOS compared with males but the difference was not statistically significant for both the mean and median values. The unadjusted HR showed that females were $15 \%$ less likely to be discharged earlier compared to males (unadjusted HR 0.85; $\mathrm{p}=0.0070$ ). However because the proportional hazard assumption did not hold for gender $(p=<0.0001)$, the multivariate model was stratified by gender. No results for gender were presented for the stratified model because stratified Cox model does not report HRs for stratified variables.

There was a significant association between deprivation status of place of residence and LOS with those in the more deprived areas tending to stay longer on admission. Compared with second IMD quintile areas, those from fifth quintile areas were $35 \%$ less likely to be discharged earlier (adjusted HR 0.65; $\mathrm{p}=0.0010$ ), those from the fourth IMD quintile areas were $43 \%$ less likely to be discharged earlier (adjusted HR 0.57; $<<0.0001$ ), while those from the third quintile areas were $38 \%$ less likely (adjusted HR $0.62 \mathrm{p}=0.0010$ ).

\section{LOS variations by temporal and geographical factors}

Table 2 shows the variations in LOS by temporal and geographical variables. The highest number of admissions was recorded in 2007/08 financial year while the lowest was recorded in 2006/2007. There were more admissions during December-March $(38.1 \%$ of all the admissions) compared to the other two seasons.

The average distance of the places of residence from the hospital was $2.99 \mathrm{~km}$ (95\% CI 2.94 to 3.05) with the furthest distance being $6.32 \mathrm{~km}$ and nearest $0.32 \mathrm{~km}$. Half of the patients were from within $2.75 \mathrm{~km}$ (ie, the median distance) radius of the hospital.

There was a statistically non-significant reduction in LOS over the period of the study from a median of 7 days in 2005/2006 to a median of six in 2009/2010. The corresponding mean LOS figures were 11.5 and 9.3 days, respectively. The adjusted HR showed that patients were $22 \%$ more likely to be discharged earlier in 2009/2010 compared with 2005/2006 (adjusted HR 1.22; $\mathrm{p}=0.0100$ ). Statistically significant increase in the likelihood of earlier discharge was noticed as early as 2006/2007 (adjusted HR 1.20; p: 0.0130); however, this increase was not sustained over the rest of the period.

Though the number of admissions showed seasonal variations, the LOS did not. Overall we did not notice statistically significant variations in the likelihood of earlier discharge across the three seasons. There were also no significant variations in the likelihood of earlier discharges based on distance from the hospital.

\section{LOS by health condition and health service factors}

Table 3 shows the variations in LOS by health condition and health service variables. Majority $(90.8 \%)$ of the patients were registered with Blackpool GPs. Just over $50 \%$ of the admissions were attributed to COPD with acute exacerbation, unspecified followed by COPD with acute lower respiratory infection $(40.2 \%)$. The vast majority of the admissions were managed by general medicine specialty $(90 \%)$ while $7.1 \%$ were managed by accident and emergency specialty. Admissions in patients with Charlson index of 1 were in the majority $(75.9 \%)$ while those with an index of $3+$ were in the minority $(7.3 \%)$.

There were no significant variations in LOS based on GP practice location. However, the causes of admissions were associated with LOS. Compared with admissions attributed to COPD with acute exacerbation, unspecified, admissions attributed to COPD with acute lower respiratory infection were $19 \%$ less likely to be discharged earlier (adjusted HR 0.81; $\mathrm{p}=<0.0001$ ) while there was no 
Table 2 Variations in length of stay by temporal and geographical factors

\begin{tabular}{|c|c|c|c|c|c|c|c|c|c|}
\hline Variable & $\begin{array}{l}\text { Number of } \\
\text { admissions (\%) }\end{array}$ & $\begin{array}{l}\text { Median } \\
\text { LOS (95\% } \\
\text { Cl) }\end{array}$ & Mean LOS (95\% Cl) & $\begin{array}{l}\text { Unadjusted HR } \\
(95 \% \mathrm{Cl})\end{array}$ & $\mathbf{p}$ & $\begin{array}{l}\text { p For } \\
\text { PH test }\end{array}$ & $\begin{array}{l}\text { Adjusted HR* } \\
(95 \% \mathrm{Cl})\end{array}$ & $\mathbf{p}$ & $\begin{array}{l}\text { p For } \\
\text { PH test }\end{array}$ \\
\hline \multicolumn{10}{|l|}{ Financial year } \\
\hline $2005 / 2006$ & $454(18.8 \%)$ & 7 (6 to 7$)$ & 11.54 (9.72 to 13.37$)$ & 1 & - & - & 1 & - & - \\
\hline $2006 / 2007$ & $447(18.5 \%)$ & 6 (5 to 6$)$ & $9.36(8.13$ to 10.60$)$ & 1.15 (1 to 1.33$)$ & 0.0570 & 0.8820 & $1.20(1.04$ to 1.39$)$ & 0.0130 & 0.1484 \\
\hline 2007/2008 & $535(22.2 \%)$ & 6 (5 to 6$)$ & 9.46 (7.98 to 10.93$)$ & 1.18 (1.02 to 1.36$)$ & 0.0220 & 0.8234 & 1.20 (1.04 to 1.39$)$ & 0.0120 & 0.0933 \\
\hline $2008 / 2009$ & $522(21.7 \%)$ & $6(5$ to 6$)$ & 8.86 (7.79 to 9.92$)$ & $1.20(1.04$ to 1.38$)$ & 0.0100 & 0.8428 & $1.21(1.05$ to 1.39$)$ & 0.0100 & 0.1602 \\
\hline $2009 / 2010$ & $452(18.8 \%)$ & 6 (5 to 6$)$ & 9.31 (7.96 to 10.66$)$ & 1.19 (1.03 to 1.38$)$ & 0.0210 & 0.7388 & $1.22(1.05$ to 1.42$)$ & 0.0100 & 0.2928 \\
\hline Total & $2410(100 \%)$ & $6(6$ to 6$)$ & $9.79(9.09$ to 10.50$)$ & - & - & 0.9826 & - & - & - \\
\hline \multicolumn{10}{|l|}{ Season } \\
\hline April-July & 759 (31.5\%) & $6(5$ to 6$)$ & 9.98 (8.84 to 11.13$)$ & 1 & - & - & - & - & - \\
\hline $\begin{array}{l}\text { August- } \\
\text { November }\end{array}$ & $733(30.4 \%)$ & 6 (5 to 6$)$ & 9.70 (8.54 to 10.85$)$ & 1.01 (0.91 to 1.12$)$ & 0.8330 & 0.6532 & $1.02(0.91$ to 1.13$)$ & 0.7450 & 0.9698 \\
\hline $\begin{array}{l}\text { December- } \\
\text { March }\end{array}$ & $918(38.1 \%)$ & $6(6$ to 6$)$ & 9.49 (8.44 to 10.55$)$ & $1.02(0.92$ to 1.13$)$ & 0.7040 & 0.3421 & $1.02(0.93$ to 1.13$)$ & 0.6580 & 0.8366 \\
\hline Total & $2410(100 \%)$ & $6(6$ to 6$)$ & 9.79 (9.09 to 10.50$)$ & - & - & 0.6359 & - & - & - \\
\hline \multicolumn{10}{|c|}{ Distance from hospital } \\
\hline $\begin{array}{l}\text { Distance } \\
\text { quintile } 1 \\
(0.32-1.8 \mathrm{~km})\end{array}$ & $482(20 \%)$ & $6(5$ to 6$)$ & 10 (8.67 to 11.33$)$ & 1 & - & - & 1 & - & - \\
\hline $\begin{array}{l}\text { Distance } \\
\text { quintile } 2 \\
(>1.8-2.5 \mathrm{~km})\end{array}$ & $484(20.1 \%)$ & 5 (5 to 6$)$ & 9.61 (7.66 to 11.56$)$ & $1.09(0.93$ to 1.29$)$ & 0.2940 & 0.1692 & 1.14 (0.98 to 1.33$)$ & 0.0880 & 0.4950 \\
\hline $\begin{array}{l}\text { Distance } \\
\text { quintile } 3 \\
(>2.5-3.1 \mathrm{~km})\end{array}$ & $488(20.2 \%)$ & $6(5$ to 6$)$ & 8.05 (7.29 to 8.82$)$ & $1.10(0.93$ to 1.30$)$ & 0.2520 & 0.4196 & $1.07(0.90$ to 1.26$)$ & 0.4530 & 0.3241 \\
\hline $\begin{array}{l}\text { Distance } \\
\text { quintile } 4 \\
(>3.1-4.2 \mathrm{~km})\end{array}$ & $476(19.8 \%)$ & $7(6$ to 7$)$ & 11.37 (9.90 to 12.84$)$ & 0.88 (0.75 to 1.02$)$ & 0.0870 & 0.4279 & $0.86(0.73$ to 1.01$)$ & 0.0610 & 0.5286 \\
\hline $\begin{array}{l}\text { Distance } \\
\text { quintile } 5 \\
(>4.2-6.3 \mathrm{~km})\end{array}$ & $480(19.9 \%)$ & $6(5$ to 6$)$ & 9.38 (7.87 to 10.88$)$ & 1.07 (0.89 to 1.30$)$ & 0.4630 & 0.1119 & $1.06(0.83$ to 1.35$)$ & 0.6490 & 0.6220 \\
\hline Total & $2410(100 \%)$ & $6(6$ to 6$)$ & 9.79 (9.09 to 10.50$)$ & - & - & 0.0332 & - & - & - \\
\hline
\end{tabular}

LOS, length of stay; $\mathrm{PH}$ test, proportional hazard test.

${ }^{*} \mathrm{HR}$ adjusted for all the main variables. 
Table 3 Variations in length of stay by factors associated with patient's health condition and health service factors

\begin{tabular}{|c|c|c|c|c|c|c|c|c|c|}
\hline Variable & $\begin{array}{l}\text { Number of } \\
\text { admissions (\%) }\end{array}$ & $\begin{array}{l}\text { Median LOS } \\
(95 \% \mathrm{Cl})\end{array}$ & $\begin{array}{l}\text { Mean LOS } \\
(95 \% \mathrm{Cl})\end{array}$ & $\begin{array}{l}\text { Unadjusted HR } \\
(95 \% \mathrm{Cl})\end{array}$ & $\mathbf{P}$ & $\begin{array}{l}\text { p For } \\
\text { PH test* }\end{array}$ & $\begin{array}{l}\text { Adjusted HR† } \\
(95 \% \mathrm{Cl})\end{array}$ & $\mathbf{p}$ & $\begin{array}{l}\text { p For } \\
\text { PH test }\end{array}$ \\
\hline \multicolumn{10}{|l|}{ Commissioning PCT } \\
\hline \multirow[t]{2}{*}{ Blackpool } & $2189(90.8 \%)$ & $6(6$ to 6$)$ & $\begin{array}{l}9.65 \\
(8.96 \text { to } 10.33)\end{array}$ & 1 & - & - & 1 & - & - \\
\hline & $221(9.2 \%)$ & 5 (5 to 7$)$ & $\begin{array}{l}10.66 \\
(7.88 \text { to } 13.43)\end{array}$ & $\begin{array}{l}1 \\
\text { (0.81 to } 1.24)\end{array}$ & 0.9900 & 0.0046 & $\begin{array}{l}0.97 \\
(0.76 \text { to } 1.24)\end{array}$ & 0.8300 & 0.6736 \\
\hline Total & $2410(100 \%)$ & $6(6$ to 6$)$ & $\begin{array}{l}9.79 \\
(9.09 \text { to } 10.50)\end{array}$ & - & - & 0.0046 & - & - & - \\
\hline \multicolumn{10}{|l|}{ Primary diagnosis } \\
\hline $\begin{array}{l}\text { COPD with acute } \\
\text { exacerbation, unspecified }\end{array}$ & $1210(50.2 \%)$ & 5 (5 to 6$)$ & $\begin{array}{l}8.15 \\
\text { ( } 7.57 \text { to } 8.72)\end{array}$ & 1 & - & - & 1 & - & - \\
\hline $\begin{array}{l}\text { COPD with acute lower } \\
\text { respiratory infection }\end{array}$ & $968(40.2 \%)$ & 7 (6 to 7$)$ & $\begin{array}{l}11.29 \\
(10.15 \text { to } 12.43)\end{array}$ & $\begin{array}{l}0.79 \\
(0.73 \text { to } 0.86)\end{array}$ & $<0.0001$ & 0.9057 & $\begin{array}{l}0.81 \\
(0.75 \text { to } 0.88)\end{array}$ & $<0.0001$ & 0.9192 \\
\hline Other COPD & $232(9.6 \%)$ & 5 (4 to 6$)$ & $\begin{array}{l}11.56 \\
(7.13 \text { to } 15.98)\end{array}$ & $\begin{array}{l}0.91 \\
(0.76 \text { to } 1.08)\end{array}$ & 0.2790 & 0.0047 & $\begin{array}{l}0.93 \\
(0.78 \text { to } 1.09)\end{array}$ & 0.3570 & 0.0300 \\
\hline Total & $2410(100 \%)$ & 6 (6 to 6$)$ & $\begin{array}{l}9.79 \\
(9.09 \text { to } 10.50)\end{array}$ & - & - & 0.0163 & - & - & - \\
\hline \multicolumn{10}{|l|}{ Charlson index } \\
\hline 1 & $1829(75.9 \%)$ & 6 (5 to 6$)$ & $\begin{array}{l}8.93 \\
\text { (8.33 to } 9.53)\end{array}$ & 1 & - & - & 1 & - & - \\
\hline 2 & $404(16.8 \%)$ & 7 (6 to 7$)$ & $\begin{array}{l}12.22 \\
(9.58 \text { to } 14.86)\end{array}$ & $\begin{array}{l}0.82 \\
(0.72 \text { to } 0.94)\end{array}$ & 0.0050 & 0.9038 & $\begin{array}{l}0.87 \\
(0.76 \text { to } 0.99)\end{array}$ & 0.0390 & 0.2730 \\
\hline $3+$ & $177(7.3 \%)$ & 8 (7 to 8$)$ & $\begin{array}{l}13.27 \\
(8.76 \text { to } 17.78)\end{array}$ & $\begin{array}{l}0.73 \\
(0.63 \text { to } 0.86)\end{array}$ & $<0.0001$ & 0.7163 & $\begin{array}{l}0.81 \\
(0.69 \text { to } 0.95)\end{array}$ & 0.0080 & 0.2212 \\
\hline Total & $2410(100 \%)$ & $6(6$ to 6$)$ & $\begin{array}{l}9.79 \\
(9.09 \text { to } 10.50)\end{array}$ & - & - & 0.9352 & - & - & - \\
\hline \multicolumn{10}{|l|}{ Specialty of admission } \\
\hline Accident and emergency & $171(7.1 \%)$ & $3(1$ to 5$)$ & $\begin{array}{l}5.87 \text { (4.26 to } \\
7.48)\end{array}$ & 1 & - & - & 1 & - & - \\
\hline General medicine & $2170(90 \%)$ & $6(6$ to 6$)$ & $10(9.24$ to 10.75$)$ & $\begin{array}{l}0.64 \\
(0.50 \text { to } 0.82)\end{array}$ & $<0.0001$ & 0.1253 & $\begin{array}{l}0.67 \\
(0.52 \text { to } 0.86)\end{array}$ & 0.0020 & 0.0771 \\
\hline Other & $69(2.9 \%)$ & $6(5$ to 7$)$ & $\begin{array}{l}9.21 \\
(6.39 \text { to } 12.04)\end{array}$ & $\begin{array}{l}0.64 \\
(0.47 \text { to } 0.88)\end{array}$ & 0.0060 & 0.1085 & $\begin{array}{l}0.63 \\
(0.45 \text { to } 0.88)\end{array}$ & 0.0060 & 0.0254 \\
\hline Total & $2410(100 \%)$ & $6(6$ to 6$)$ & $\begin{array}{l}9.79 \\
(9.09 \text { to } 10.50)\end{array}$ & - & - & 0.2470 & - & - & - \\
\hline
\end{tabular}


statistically significant difference between the likelihood of earlier discharge for admissions due to unspecified causes of exacerbations and admissions attributed to other COPD problems (adjusted HR 0.93; $\mathrm{p}=0.3570$ ).

Specialty of admission was also significantly associated with LOS with admissions managed by accident and emergency specialty being discharged the earliest. Compared with patients managed by the accident and emergency specialties, those managed by general medical specialties were $33 \%$ less likely to be discharged earlier (adjusted HR 0.67; $\mathrm{p}=0.0020$ ) while those managed by other specialties were $37 \%$ less likely to be discharged earlier (adjusted HR 0.63; $\mathrm{p}=0.0020$ ).

Comorbid conditions in patients were associated with LOS. Those with Charlson index of 1 experienced the shortest LOS while those with Charlson index of 3+ experienced the longest. Compared with patients with index 1, those with index 2 were 13\% less likely to be discharged earlier (adjusted HR 0.87; $\mathrm{p}=0.0390$ ) while those with index $3+$ were $19 \%$ less likely to be discharged earlier (adjusted HR 0.81; $\mathrm{p}=0.0080$ ).

\section{Interactions}

We noticed statistically significant association for two of the interaction terms (ie, IMD quintilexseason and age group $\times$ distance) and presented the results for them only (table 4). We did not observe significant association for the rest.

In the second IMD quintile areas, admissions during August-November were $94 \%$ more likely to be discharged earlier compared with admissions during AprilJuly (adjusted HR 1.94; $\mathrm{p}=0.0150$ ) but in the fourth and fifth deprivation quintile areas the effects were reversed. In the fourth IMD quintile areas, admissions during August-November were $45 \%$ less likely to be discharged earlier compared with admissions during April-July

Table 4 HRs associated with the interaction terms

\begin{tabular}{|c|c|c|c|}
\hline Interaction term & Adjusted HR (95\% Cl) & p Value & $\begin{array}{l}\mathrm{p} \text { For likelihood } \\
\text { ratio test }\end{array}$ \\
\hline \multicolumn{4}{|l|}{ Season×IMD } \\
\hline [2nd quintile] $\times[$ Apr-Jul] $\dagger$ & 1 & - & 0.6943 \\
\hline [3rd quintile] $\times[$ Apr-Jul] $\dagger$ & $0.74(0.51$ to 1.06$)$ & 0.1040 & \\
\hline [4th quintile $] \times[\mathrm{Apr}-\mathrm{Jul}] \dagger$ & $0.66(0.47$ to 0.92$)$ & 0.0140 & \\
\hline [5th quintile $] \times[\mathrm{Apr}-\mathrm{Jul}] \dagger$ & $0.74(0.53$ to 1.04$)$ & 0.0800 & \\
\hline [Aug-Nov] $\times$ [2nd quintile] & 1.94 (1.14 to 3.31$)$ & 0.0150 & \\
\hline [Dec-Mar] $\times$ [2nd quintile] & 1.24 (0.68 to 2.27$)$ & 0.4880 & \\
\hline [Aug-Nov] $\times[3$ rd quintile] & $0.59(0.31$ to 1.11$)$ & 0.1020 & \\
\hline [Dec-Mar] $\times[3 r d$ quintile] & $0.86(0.44$ to 1.67$)$ & 0.6500 & \\
\hline [Aug-Nov] $\times$ [4th quintile] & 0.55 (0.31 to 0.97$)$ & 0.0380 & \\
\hline [Dec-Mar] $\times[4$ th quintile] & $0.87(0.46$ to 1.65$)$ & 0.6680 & \\
\hline [Aug-Nov $] \times[5$ th quintile $]$ & 0.49 (0.28 to 0.85$)$ & 0.0120 & \\
\hline [Dec- Mar] $\times[$ th quintile] & $0.79(0.43$ to 1.47$)$ & 0.4560 & \\
\hline \multicolumn{4}{|l|}{ Agexdistance } \\
\hline [40-59]×[Distance-q1]† & 1.00 & - & 0.0055 \\
\hline [60-69]×[Distance-q1]† & $0.79(0.60$ to 1.05$)$ & 0.1050 & \\
\hline$[70-79] \times[$ Distance-q1]† & 0.52 (0.38 to 0.72$)$ & $<0.0001$ & \\
\hline$[80+] \times[$ Distance-q1] $\dagger$ & 0.44 (0.31 to 0.63$)$ & $<0.0001$ & \\
\hline [40-59]×[Distance-q2] & $1.03(0.78$ to 1.35$)$ & 0.8570 & \\
\hline [40-59]×[Distance-q3] & 0.95 (0.69 to 1.29$)$ & 0.7310 & \\
\hline$[40-59] \times[$ Distance-q4] & 0.55 (0.39 to 0.76$)$ & $<0.0001$ & \\
\hline [40-59]×[Distance-q5] & 0.84 (0.52 to 1.37$)$ & 0.4930 & \\
\hline [60-69]×[Distance-q2] & $1.19(0.82$ to 1.74$)$ & 0.3620 & \\
\hline [60-69]×[Distance-q3] & $0.96(0.65$ to 1.43$)$ & 0.8470 & \\
\hline [60-69]×[Distance-q4] & 1.54 (1.03 to 2.31$)$ & 0.0360 & \\
\hline [60-69] $\times[$ Distance-q5] & $1.13(0.64$ to 2.00$)$ & 0.6790 & \\
\hline [70-79] $\times[$ Distance-q2] & $1.11(0.74$ to 1.69$)$ & 0.6130 & \\
\hline [70-79]×[Distance-q3] & 1.45 (0.89 to 2.35$)$ & 0.1350 & \\
\hline [70-79]×[Distance-q4] & 1.68 (1.10 to 2.58$)$ & 0.0170 & \\
\hline [70-79] $\times[$ Distance-q5] & 1.57 (0.88 to 2.82$)$ & 0.1300 & \\
\hline$[80+] \times[$ Distance-q2] & $1.17(0.75$ to 1.84$)$ & 0.4820 & \\
\hline$[80+] \times[$ Distance-q3] & $1.13(0.70$ to 1.83$)$ & 0.6160 & \\
\hline$[80+] \times[$ Distance-q4] & 2.25 (1.41 to 3.60$)$ & 0.0010 & \\
\hline$[80+] \times[$ Distance-q5] & $1.33(0.76$ to 2.35$)$ & 0.3200 & \\
\hline
\end{tabular}

*See http://128.97.141.26/stat/stata/webbooks/logistic/chapter2/default.htm for a detailed explanation of interpreting interaction terms. †Baseline risk for within subgroup comparisons.

q1, q2, q3, q4 and q5: first, second, third, fourth and fifth quintiles. 
(adjusted HR 0.55; $\mathrm{p}=0.0380$ ) while in the fifth IMD quintile areas, they were $51 \%$ less likely to be discharged earlier compared with admissions during April-July (adjusted HR 0.49; $\mathrm{p}=0.0120$ ). We did not find significant variations in the likelihood of earlier discharge between admissions in April-July and December-March across the second, fourth and fifth quintiles. There were no statistical significant seasonal variations in the LOS for admissions from the third deprivation quintile areas.

Across all age groups, admissions from the fourth distance quintile areas (ie, within $3.1-4.2 \mathrm{~km}$ radius of the hospital) were significantly more likely to be discharged earlier compared with those living within the first quintile distance of the hospital. This effect increases with age with those aged 80+ and living within fourth distance quintile of the hospital being more than two times more likely to be discharged earlier compared with their counterparts living within the first distance quintile of the hospital (adjusted HR 2.25; $\mathrm{p}=0.0010$ ). The interaction term significantly contributed to the fit of the model $(\mathrm{p}=0.0055)$.

\section{DISCUSSION}

\section{Main findings in relation to the literature}

LOS for COPD patients have reduced over the period of our study. This was in keeping with national and international trends which have also been associated with increasing re-admission rates ${ }^{8} 1227$ raising the question whether there could be an optimum LOS for COPD patients. Though some have suggested 7 days as an optimum associated with the lowest re-admission rates ${ }^{11}$ others found no association between re-admission rates and LOS. ${ }^{28}$ The apparent inconsistencies in the evidence about re-admission risk from existing literature may be due to developments in postdischarge management. ${ }^{11}$

Older patients were more likely to stay longer on admission. This may be because they might have been in poorer functional states ${ }^{27}$ and these were not accounted for in our study. The literature also indicates that LOS tended to increase with age. ${ }^{29}{ }^{30}$ Old age is also associated with general physical frailty that could delay recovery.

We found that males were more likely to be discharged earlier than females though the proportional hazard assumption did not hold. There is some evidence from the existing literature ${ }^{11} 31$ supporting our observation though the reasons for this are not apparent.

We also found that admissions from more deprived areas were more likely to stay longer in hospital possibly due to them having more severe underlying health conditions. COPD admissions are most frequent in deprived areas. ${ }^{17} 32$ The combination of frequent admissions and prolonged LOS will accentuate the cost burden of COPD in deprived areas.

Though we did not notice an overall seasonal variation in LOS, we observed seasonal variations across the deprivation quintiles. Those in the most deprived areas were less likely to be discharged early during AugustNovember. This may be a reflection of the need to involve other services (eg, social services) in the care of the patients from more deprived areas in the run up to the winter. There is some evidence showing that the need for social work intervention may be linked to prolonged LOS in patients with acute exacerbations. ${ }^{33}$

Exacerbations due to infective causes were associated with longer LOS in our study. This is supported by findings in the UK. ${ }^{34}$ The risk of respiratory infection is highest during the winter. ${ }^{35}{ }^{36}$ Infective causes of exacerbations are therefore expected to be higher in the winter and may be associated with longer LOS. It is thus surprising that our data did not show any significant seasonal variation in both univariate and multivariate analyses though such variations had been noticed elsewhere. ${ }^{37}$ Implementation of supported discharge schemes in Blackpool and hospital bed management pressures during the winter might have contributed to the attenuation in seasonal variations.

Patients treated by general medical specialties were most likely to stay longer. This may be due to the complex comorbid conditions managed by these specialties. There is however evidence suggesting that LOS are influenced by managing physician attributes and the quality of care organisation. ${ }^{30} 38$ Patients admitted under care of the elderly physicians have been found to be less likely to enter early discharge schemes. ${ }^{29}$

Comorbidities were independent predictors of LOS in our study. This has been found by others as well. ${ }^{39}{ }^{40} \mathrm{It}$ is reasonable to expect LOS to be longer in patients with multiple underlying health conditions some of which may be related to COPD.

Generally the distance of place of residence from hospital was not associated with LOS but analysis based on interaction between age group and distance showed that across all the age groups, those living within $3.1-4.2 \mathrm{~km}$ radius of the hospital were most likely to be discharged earlier. This may be a feature associated with service configurations and possibly the effects of living conditions not adequately captured by the IMD scores. Though we have not come across any study on the impact of distance of patients' places of residence from hospital on COPD admission outcomes, Purdy et $a l^{17}$ found that distance to the nearest emergency department was significantly associated with risk of admission for respiratory condition.

\section{Implications for practice}

Those from more deprived areas may suffer more seriously from COPD and comorbidities and may make proportionately higher demand on services. To reduce these pressures, improving access to measures aimed at reducing exacerbations, for example, pulmonary rehabilitation services, may need to be better focused on these areas.

Effects of early discharge schemes on seasonal variations in LOS, and admission and re-admission frequencies will need to be evaluated to ensure optimal care is provided across all the seasons and that the 'revolving door' phenomenon ${ }^{11}$ is not operating. 
LOS is routinely used by health authorities to determine efficiency in care provision. Given the fact that no optimum LOS has been identified for COPD patients, if LOS is used without case-mix considerations it could lead to inappropriate inferences about efficiency.

\section{Limitations of the study}

Incompleteness and inaccuracy are the main problems associated with routine data sources. Even though there have been concerns about the quality of routine hospital data, data quality in the UK has improved greatly over the years. ${ }^{41}$ The dataset we used is one of the standard datasets used for performance monitoring, reconciliation and payments in the National Health Service and supports the implementation of the UK Department of Health payment by result policy. ${ }^{42}$

This study was on a patient population in a defined geographical area. This has implications for its generalisability as factors such as patient profile, seasonal influences and service configuration could influence outcomes.

Other likely predictors of LOS, for example, severity of the primary diagnoses and comorbidities, performance status and availability and quality of other health and social services were not included in the regression models because they were not available in the dataset. We did not include admission method and discharge destination because very few patients were in some of the categories to permit appropriate analyses. Additionally there was no information on the discharge destination (ie, where they would have been discharged to should their clinical management achieve the outcome of being fit enough to leave hospital) for those whose data were censored. We used Charlson index to model the effect of comorbidities. Some have observed that the exclusive use of the index may underestimate comorbidities in COPD patients. ${ }^{43}$

We used the 2010 IMD, a population level measure of deprivation, to assess the association between level of deprivation and LOS. Though IMD is widely used in studies to assess the effect of socioeconomic deprivation on health outcomes, it could predispose to ecological fallacy because associations at the population level may not necessarily represent associations at an individual level. ${ }^{44}$

Finally readers need to be cautious in interpreting these associations between LOS and the factors of interest because the associations do not necessarily imply causation.

\section{CONCLUSION}

LOS among COPD patients have reduced over the period of the study. Age, deprivation, Charlson index, specialty of admission and cause of exacerbations were independently associated with LOS. We did not find significant associations between LOS and season of admission and distance of place of residence from hospital but there were significant variations in LOS for these variables based on selected patient characteristics.
Contributors All authors contributed to various aspect of this paper. They all read and approved the final submission. GA was involved in study design, data processing and statistical analyses, interpretation and writing of the manuscript. JP was involved in data cleaning and processing, anonymisation, interpretation and critical comments. LD was involved in study design, writing of manuscript and critical comments.

Competing interests None.

Ethics approval Ethics approval was not required for the routine data used for this study as the main aim of the study is to inform delivery of best care. ${ }^{45}$

Provenance and peer review Not commissioned; externally peer reviewed.

Data sharing statement There are no additional data available.

\section{REFERENCES}

1. Mathers CD, Loncar D. Projections of global mortality and burden of disease from 2002 to 2030. PLoS Med 2006;3:e442.

2. Commission for Healthcare Audit and Inspection. Clearing the air: a national study of chronic obstructive pulmonary disease. London: Healthcare Commission, 2006

3. The NHS Information Centre. Hospital Episode Statistics for England. Inpatient statistics, 2009-10. The NHS Information Centre 2011; http://www.hesonline.org.uk/Ease/ContentServer?sitelD= 1937\&categoryID=192 (accessed 27 Sep 2011).

4. Halpin DMG, Miravitlles M. Chronic obstructive pulmonary disease: the disease and its burden to society. Proc Am Thorac Soc 2006;3:619-23.

5. Dalal AA, Christensen L, Liu F, et al. Direct costs of chronic obstructive pulmonary disease among managed care patients. Int J Chron Obstruct Pulmon Dis 2010;5:341-9.

6. Pride NB, Soriano JB. Chronic obstructive pulmonary disease in the United Kingdom: trends in mortality, morbidity, and smoking. Curr Opin Pulm Med 2002;8:95-101.

7. Britton M. The burden of COPD in the U.K.: results from the Confronting COPD survey. Respir Med 2003;97(Suppl C):S71-9.

8. Sullivan SD, Ramsey SD, Lee TA. The Economic Burden of COPD. Chest 2000;117:5S-9S.

9. Pushparajah S, Mcclellan R, Henry A, et al. Use of a chronic disease management programme in COPD to reduce hospital admissions. Chron Respir Dis 2006;3:187-93.

10. Utens CM, Goossens LM, Smeenk FW, et al. Effectiveness and cost-effectiveness of early assisted discharge for chronic obstructive pulmonary disease exacerbations: the design of a randomised controlled trial. BMC Public Health 2010;10:618.

11. Saynajakangas $\mathrm{O}$, Kinnunen $\mathrm{T}$, Tuuponen $\mathrm{T}$, et al. Length of stay and interval to readmission in emergency hospital treatment of COPD. Age Ageing 2004;33:567-70.

12. Department of Health. Consultation on a strategy for services for Chronic Obstructive Pulmonary Disease (COPD) in England. London: Department of Health, 2010. http://webarchive. nationalarchives.gov.uk/+/www.dh.gov.uk/en/consultations/ liveconsultations/dh_112977 (accessed 20 Oct 2011).

13. Donaldson GC, Wedzicha JA. COPD exacerbations. 1: epidemiology. Thorax 2006;61:164-68.

14. Office for National Statistics. Mid-2010 population estimates for primary care organisations in England by single year of age and sex. Mid-year population estimates 2011; http://www.ons.gov.uk/ons/ taxonomy/index.html?nscl=Population+Estimates (accessed 10 Oct 2011).

15. National Centre for Health Outcomes Development. Prevalence: chronic obstructive pulmonary disease. NCHOD 2011;http://www. nchod.nhs.uk (accessed 29 Sep 2011).

16. The Marmot Review Team. Fair society, healthy lives-the marmot review. London: The Marmot Review; 2010. http://www. instituteofhealthequity.org/projects/fair-society-healthy-lives-themarmot-review (accessed 03 May 2012).

17. Purdy S, Griffin T, Salisbury C, et al. Emergency respiratory admissions: influence of practice, population and hospital factors $J$ Health Serv Res Policy 2011;16:133-40.

18. Office for National Statistics. Winter mortality. ONS 2010; http://www. statistics.gov.uk/cci/nugget.asp?id=574 (accessed 23 Feb 2010).

19. NHS Data Model and Dictionary Service. Commissioning data set. National Health Service. London: National Health Service; 2010. http://www.datadictionary.nhs.uk/retired/data_dictionary/messages/ commissioning_data_set_v5/admitted_patient_care_cds_type_-_ general_episode_fr.asp?shownav=1 (accessed 07 Jul 2011). 
20. The NHS Information Centre. How do you spell that? Hospital Episode Statistics 2010; http://www.hesonline.nhs.uk/Ease/servlet/ ContentServer?sitelD=1937\&categoryID=1072 (accessed 19 Mar 2010).

21. World Health Organisation. International Statistical Classification of Diseases and Related Health Problems - 10th Revision, Version for 2007. WHO 2010;http://apps.who.int/classifications/apps/icd/ icd10online/ (accessed 07 Jul 2011).

22. Charlson ME, Pompei $\mathrm{P}$, Ales $\mathrm{KL}$, et al. A new method of classifying prognostic comorbidity in longitudinal studies: development and validation. J Chronic Dis 1987;40:373-83.

23. Department for Communities and Local Government. The English indices of deprivation 2010. London: Department for Communities and Local Government, 2011. http://www.communities.gov.uk/ publications/corporate/statistics/indices2010 (accessed 09 Jun 2011).

24. Gardiner JC. Survival analysis: overview of parametric, nonparametric and semiparametric approaches and new developments. SAS Global Forum 2010. Statistics and Data Analysis. 2010. http://support.sas.com/resources/papers/ proceedings10/252-2010.pdf (accessed 07 Jul 2011).

25. Jin $\mathrm{H}, \mathrm{Lu} \mathrm{Y}$, Stone $\mathrm{K}$, et al. Alternative tree-structured survival analysis based on variance of survival time. Med Decis Making 2004;24:670-80.

26. UCLA Academic Technology Services. Survival Analysis with Stata. Statistical Consulting Group 2011; http://www.ats.ucla.edu/ stat/stata/seminars/stata_survival/default.htm (accessed 26 Sep 2011).

27. George PM, Stone RA, Buckingham RJ, et al. Changes in NHS organization of care and management of hospital admissions with COPD exacerbations between the national COPD audits of 2003 and 2008. QJM 2011;104:859-66.

28. Almagro $\mathrm{P}$, Barreiro B, Ochoa de EA et al. Risk factors for hospital readmission in patients with chronic obstructive pulmonary disease. Respiration 2006;73:311-17.

29. Connolly MJ, Lowe D, Anstey K, et al. Admissions to hospital with exacerbations of chronic obstructive pulmonary disease: effect of age related factors and service organisation. Thorax 2006;61:843-8.

30. Verdaguer MA, Peiro S, Librero J. Variations in the use of hospital resources in treating patients with chronic obstructive pulmonary disease. Arch Bronconeumol 2003;39:442-8.

31. Keistinen T, Vilkman S, Tuuponen T, et al. Hospital admissions for chronic obstructive pulmonary disease in the population aged 55 years or over in Finland during 1972-1992. Public Health 1996;110:257-9.

32. Calderon-Larranaga A, Carney L, Soljak M, et al. Association of population and primary healthcare factors with hospital admission rates for chronic obstructive pulmonary disease in England: national cross-sectional study. Thorax 2011;66:191-6.
33. Wong AW, Gan WQ, Burns J, et al. Acute exacerbation of chronic obstructive pulmonary disease: influence of social factors in determining length of hospital stay and readmission rates. Can Respir J 2008;15:361-4.

34. Myint PK, Lowe D, Stone RA, et al. UK National COPD Resources and Outcomes Project 2008: patients with Chronic Obstructive Pulmonary Disease exacerbations who present with radiological pneumonia have worse outcome compared to those with non-pneumonic chronic obstructive pulmonary disease exacerbations. Respiration 2011;82(4):320-7.

35. Makinen TM, Juvonen R, Jokelainen J, et al. Cold temperature and low humidity are associated with increased occurrence of respiratory tract infections. Respir Med 2009;103:456-62.

36. Mourtzoukou EG, Falagas ME. Exposure to cold and respiratory tract infections. Int J Tuberc Lung Dis 2007;11:938-43.

37. Kinnunen T, Saynajakangs O, Tuuponen T, et al. Regional and seasonal variation in the length of hospital stay for chronic obstructive pulmonary disease in Finland. Int $J$ Circumpolar Health 2002;61:131-5.

38. Price LC, Lowe D, Hosker HS, et al. UK National COPD Audit 2003: impact of hospital resources and organisation of care on patient outcome following admission for acute COPD exacerbation. Thorax 2006;61:837-42.

39. Baker $\mathrm{EH}$, Janaway $\mathrm{CH}$, Philips $\mathrm{BJ}$, et al. Hyperglycaemia is associated with poor outcomes in patients admitted to hospital with acute exacerbations of chronic obstructive pulmonary disease. Thorax 2006;61:284-9.

40. de la Iglesia F, Valino P, Pita S, et al. Factors predicting a hospital stay of over 3 days in patients with acute exacerbation of chronic obstructive pulmonary disease. J Intern Med 2002;251:500-7.

41. Audit Commission. Information and data quality in the NHS. Health Bulletin. London: Audit Commission, 2004. http://www. audit-commission.gov.uk/nationalstudies/health/other/Pages/ informationanddataqualityinthenhs.aspx (accessed 19 Mar 2010).

42. NHS Connecting for Health. Secondary uses service. National Health Service. London: National Health Service, 2010. http://www. connectingforhealth.nhs.uk/systemsandservices/sus (accessed 19 Mar 2010)

43. Almagro P, Lopez GF, Cabrera F, et al. Comorbidity and gender-related differences in patients hospitalized for COPD. The ECCO study. Respir Med 2010;104:253-9.

44. Memon A. Epidemiological understanding: an overview of basic concepts and study designs. In: Pencheon D, Guest C, Melzer D, et al. Oxford handbook of public health practice. 2 nd edn. New York: Oxford University Press; 2008:100-11.

45. National Research Ethics Service. Defining research. London: National Patient Safety Agency; 2009. http://www.nres.npsa.nhs.uk/ applications/apply/is-your-project-research/ (accessed 20 Apr 2010). 